\title{
Uma voz profética ou "o segredo de olhar o sol de frente": a juventude na obra de Fernando Namora ${ }^{1}$
}

António Pedro Pita

Universidade de Coimbra

Resumo: Neste ensaio, percorre-se a ficcionalização da experiência da juventude na obra do autor de As Sete Partidas do Mundo, vivida na segunda metade dos anos trinta e na primeira dos quarenta, os anos de afirmação da jovem geração neorrealista de Coimbra. A “juventude”, enquanto tema e experiência omnipresentes na obra de Fernando Namora, é o nome para a capacidade de profecia dos pontos de fratura cultural entre a tradição e a novidade.

Palavras-chave: juventude, Coimbra, profecia, tradição, novidade

Abstract: This essay explores fictional representations of young adulthood in the novel As Sete Partidas do Mundo (Seven Departures from the World), set in the second half of the 1930 s and the first years of the 1940s. These years coincide with the period of consolidation for the neo-realist generation from the city of Coimbra. "Youth", as omnipresent theme and represented experience in the writing by Fernando Namora, becomes the metaphor for future cultural fissures between tradition and innovation.

Keywords: Youth, Coimbra, prophecy, tradition, innovation 
"A juventude tem uma voz profética”

F. Namora, Um Sino na Montanha

A juventude ocorre na obra de Fernando Namora em duas distintas configurações: como “experiência” e como “tema”. Estão relacionadas entre si e poderá ser interessante perceber como é que a "experiência” se transforma em “tema”. Mas há vantagens expositivas em autonomizar cada uma destas configurações.

I.

Em jeito de prólogo, vale a pena lembrar a importância da “juventude” como traço da autoconsciência geracional em que Fernando Namora se considerou integrado. É inevitável fazer uma referência rápida ao neorrealismo que foi menos um corpus estético-doutrinário em que um conjunto de jovens artistas se reviu e que se teria imposto, como programa, às respetivas práticas do que uma determinada relação entre "campo de experiência" e "horizonte de expetativa, ${ }^{2}$ relação $o^{3}$ em que se originaram universos tão diferentes como, e são só exemplos, os de Carlos de Oliveira, João José Cochofel, Fernando Lopes-Graça, Júlio Pomar ou José Marmelo e Silva.

A “juventude” constituiu, de facto, um dos traços ideológicos mais expressivos da autoconsciência da autonomia do neorrealismo relativamente a outras orientações doutrinárias e estéticas. Com ela quis assinalar-se não tanto a juventude dos principais promotores mas, sobretudo, a novidade dos pressupostos teóricos que esse grupo tinha consciência de disseminar nas elites culturais e políticas portuguesas e a consciência da universalidade desses elementos doutrinários. São, por isso, muito significativas as seguintes expressões do Prefácio - podemos dizer: editorial ou manifesto - que abre a revista (atenção ao título!) "Cadernos da Juventude”: "Para nós, a juventude vale na medida em que possui a consciência da sua universalidade e a noção bem viva da sua posição no mundo como elemento essencial de fecunda transformação”. Por outras palavras: para ser-se efetivamente jovem, quer dizer: culturalmente jovem, é preciso que aquele que é jovem em idade transforme a particularidade em que espontaneamente toma consciência de si numa universalidade na qual o sentido progressivo do mundo se descobre. ${ }^{4}$

A Coimbra no trânsito dos anos trinta para os anos quarenta reunia condições propícias a que essa transformação de consciências se tornasse uma aventura coletiva e solidária: um círculo universitário populacionalmente reduzido, muito concentrado do ponto de vista urbanístico e com alguns polos de atratividade onde jovens culturalmente afins se reuniam para discutir, organizar e conspirar. Falo dos cafés onde pontificavam o muito mais velho Afonso Duarte, o germanista e tradutor Paulo Quintela, o escritor Miguel Torga e, com intermitências, Vitorino Nemésio; a casa de família de João José Cochofel, cujo endereço (Rua do Loureiro, 9) é o de aventuras 
editoriais como as revistas Altitude e Vértice (após a sua refundação de 1944-45) e a coleção Novo Cancioneiro; o quarto de Raúl Castro; a sede da Associação Académica de Coimbra, com intensa e diversificada atividade e de coletividades populares de cultura, como o Ateneu de Coimbra; a redação executiva da revista Sol Nascente (embora sempre tivesse mantido o endereço portuense, instalou em Coimbra a sua efetiva redação).

São numerosos e significativos os testemunhos desse enlace profundo entre a consciencialização político-cultural e a densidade dos laços afetivos.

Na Autobiografia, Fernando Namora sintetizou: "Coimbra é um molde" (1987: 25) Num texto evocativo de Augusto dos Santos Abranches chamou-lhe "mafia":

Não há muito que um profissional da discórdia me dizia, revoltado: “Não sei que a mafia é a vossa. Impossível arrancar-vos uma palavra de desapreço por alguns dos que foram vossos companheiros na juventude, mesmo que a gente que ela quer explodir. Convosco, nada há a fazer.” Não, não há. Os caminhos divergiram, outros laços, outras afinidades, vieram interpor-se, mas por fundas que sejam as desavenças e sedutoras as armadilhas, o afeto desses tempos perdura quando não houve traição. Olhamo-nos olhos nos olhos. É um olhar às vezes magoado, mas sem rugas, sem espadas, que permite sempre voltar ao ponto de partida. (Namora 1997: 203)

Nessa autoconsciência geracional, “juventude” está associada à noção de rutura que consuma a inquietação provocada por circunstâncias históricas novas. É a chave mais geral para uma compreensão da juventude. A obra de Fernando Namora está percorrida pelos múltiplos planos em que esta compreensão se desdobra.

2.

As Sete Partidas do Mundo, romance publicado em 1938 mas iniciado em 1936, é a ficção de uma ontogénese: a personagem está dividida entre a incerteza do apelo do mundo, em que o desconhecido se apresenta na dupla face de atração e medo, e a segurança do meio familiar e suas extensões. O romance está, inteiro, no tópico da adolescência. Mas o seu alcance estético e histórico-cultural residem no modo como é resolvido esse conflito: é resolvido em favor da descoberta da assunção da historicidade das consciências e das práticas humanas. Apesar de tudo: apesar das hesitações, apesar do poder da tradição, apesar da força da família que contribuem para a conservação das condições sociais, é possível uma transformação libertadora das consciências individuais. A juventude é, por excelência (para não dizer, por natureza), o tempo e o modo desse processo de rutura com a tradição e de intuição do novo. Um retrato do jovem Fernando Namora sem dificuldade o surpreenderia nos labirintos, por vezes dramáticos, desse processo. Mas é a filtragem literária dessa experiência humana, revisitada, que revela a tematização múltipla da questão. 
A complexa arquitetura romanesca de Fogo na Noite Escura, publicado em 1943 mas iniciado em 1939, logo a seguir à edição de As Sete Partidas do Mundo, coloca em cena múltiplas possibilidades de resposta às mesmas solicitações históricas: várias consciências individuais em devir para uma constelação de convicções provocada pela eficácia histórica das mesmas condições. ${ }^{6}$

A transfiguração ficcional da casa de João José Cochofel adensa o significado desse grupo que considera um imperativo existencial fazer as ruturas historicamente necessárias à revitalização do mundo. Lê-se a dado passo: "A juventude é a única justificação que temos para a vida. Os problemas do mundo foram os homens exaustos, ressentidos, que os inventaram ou provocaram. Mas a mocidade denuncia-os, salta-lhe por cima. Ah, Zé Maria: tenha a juventude as perplexidades e as dúvidas que tiver, ela será sempre um fogo na noite mais escura” (Namora 1943: 56).

O passo justificaria uma análise demorada. Há uma rápida, certamente longínqua, ressonância de elementos nietzschianos, o "ressentimento" e o “cansaço".

No entanto, permito-me sublinhar um ponto: a atualidade como problema, na condição de a expressão ser entendida num sentido trans-histórico.

3.

A crítica obstinada em prender Namora ao neorrealismo por sua vez preso aos aspetos conjunturais dos acontecimentos dos anos 30 e 40 poderá identificar os "problemas do mundo" com as conhecidas circunstâncias: a ascensão do nazifascismo, a afirmação de Estados Novos em Portugal e no Brasil, a Guerra de Espanha, a Segunda Guerra Mundial, etc. Se não está errado, é parcial. Um fragmento de Jornal Sem Data pode esclarecer: "Se verdadeiramente existimos, essa existência não pode reduzir-se a uma época. Quem está no tempo tem de estar simultaneamente fora dele" (Namora 1988: 29). Resisto a sublinhar outras ressonâncias, porventura inesperadas (Régio ou Agamben, por exemplo). Circunscrevo-me aos limites mais estritos da questão em apreço. Embora se refira a acontecimentos cronologicamente próximos, a expressão de 1943 (“os problemas do mundo”) levanta problemas de longa duração. 0 ressentimento e o cansaço estão relacionados com aqueles problemas mas também, podemos dizê-lo hoje, com muitos outros que se lhe seguiram - o que estabelece o presente (todo o presente) como um diversificado e longo problema.

A juventude diagnostica (ou pelo menos intui) os problemas imanentes a cada configuração histórica do mundo. Dito por outras palavras: juventude é o nome para a capacidade de profecia ${ }^{7}$ dos pontos de fratura cultural entre a tradição e a novidade (Namora 1998: 31-33).

Na diversidade de dispositivos textuais - poesia, ficção,crónica, biografia -,cujas fronteiras e interpenetrações ficarão agora fora de análise, encontramos ao longo de toda a obra de Fernando Namora a seguinte problemática: o que designamos genericamente por “sociedade” é um “dispositivo de controle” (cf. Deleuze 1990: 227-247) 
que permite aos cidadãos graus diferentes de afirmação individual e de grupo, entre os limites extremos do conformismo que aniquila singularidades individuais e da ambição de uma alteridade global e absolutamente reconfiguradora do comum social. Mas estes extremos não são simétricos. Nas obras de ficção e assentando o foco na sociedade portuguesa, Namora procede a uma descrição do conformismo: não do conformismo como situação ou como estádio mas do conformismo como força que acaba por vencer mesmo as forças que se lhe queiram opor. É o grito de alerta de Fogo na Noite Escura: é preciso permanecer ativo perante as ofensivas do conformismo.

\section{$4 .^{8}$}

Ocupado em “inventariar o homem português” (Namora 1988: 38) e pressupondo que o universo rural "representa a panorâmica social mais caraterizável e mais urgente” (Namora 1996: 14), procede a essa descrição do conformismo por interpostas tramas ficcionais à primeira vista dela relativamente distantes, embora a transformação histórica do rural em urbano, isto é: a "rutura com o (chamado) meio rural" (Namora 1997: 554), seja uma das coordenadas do problema.

5.

Em O Homem Disfarçado [1957], a questão reocupa uma centralidade que talvez não tivesse, entretanto, perdido. É João Eduardo que (se) interroga: “Tornava-se então necessário que cada um se destruísse a si próprio, contemporizando com uma sociedade corrupta, lisonjeando-a e adaptando-se ao seu jogo, para não ser espezinhado economicamente? Seria essa a única saída - cada um estender a mão para as suas ruínas e reconstruir delas qualquer coisa amorfa que os outros moldavam como bem lhes apetecia?" (Namora 1997: IOI). Por outras palavras: o fogo da juventude vai ser apagado necessariamente pelas razões de uma estrutura social que corresponde a um sistema económico incoerente? (idem: 551-552). Num diálogo central do romance, João Eduardo recebe a resposta que temia: “Todo o homem verdadeiro traz da juventude uma direção. Depois, só lhe resta ter vergonha e ser-lhe fiel; ou, então, apodrecer" (Namora 1997: 114).

À medida que envelhecem, isto é: que vão tendo passados cada vez mais longos, as personagens de Fernando Namora vão encarnando experiências múltiplas da vida na sociedade salazarista sobredeterminada pelo capitalismo nacional e internacional. São experiências densas e jamais reduzidas a estereótipos (a sua complexidade mostra, aliás, o que é o neorrealismo em devir), obsessivamente confrontadas com um núcleo trans-histórico de possibilidades que obriga moralmente para toda a existência. No horizonte secularizado em que tomou forma a obra de Fernando Namora, o fundamento dessa "direção" ("todo o homem verdadeiro traz da juventude uma direção”) só pode resultar do modo como cada um teve a coragem de escolher a maioridade, o modo como cada um foi capaz de responder às "solicitações e emboscadas" 
de um tempo cruel.

A juventude é, pois, uma experiência omnipresente na obra de Fernando Namora porque não é uma fase ou um período mas é coextensiva à existência toda dos homens. De certo modo, a juventude permanece neles - desfigurada, eventualmente traída - mas presente, sempre, como ferida ou dor que, a um tempo, são a própria face do mundo e a razão para encontrar uma saída e libertar-se.

Ora, como é correlativa da tomada de consciência da deformação a que o controle social obriga a "direção" que se traz da juventude, a "saída" percorre também a obra de Fernando Namora.

6.

Os Clandestinos, romance publicado em 1972 mas escrito entre abril de 1963 e dezembro de 1971, ficciona as dimensões múltiplas dessa implicação. Ao situar o romance no ambiente antifascista do século XX português (e referindo-o, assim, a um plano de clandestinidade), Fernando Namora mostra até onde o salazarismo perverteu as consciências, como foi capaz de contaminar as consciências individuais e de grupo que se the opunham e, sobretudo, como estas consciências se deixaram contaminar, ao ponto de gerarem vidas costuradas por falsidades e mentiras (segundo nível de clandestinidade). Logo no primeiro capítulo, enquanto espera a amante no $5^{0}$ andar, frente, de um prédio burguês de Lisboa, ao interrogar-se "como pudera chegar àquilo?" (Namora 1998: 39), Vasco Rocha, escultor, militante antifascista e ex-preso político, mergulhado numa degradação que se escondia "numa zona de clandestinidade" (idem: 31 ), encarna todo o problema. Como artista, tornou-se dependente do gosto dos "bons clientes burgueses" (idem: 95) para assegurar "o desafogo económico que ele, ulcerado nas misérias da juventude, já não podia dispensar" (ibidem). Como homem, está cansado, tal os amigos próximos:

Cansados também daquele inconformismo subterrâneo que fora, na juventude, revolta, revolta da inteligência e das entranhas e agora se apaziguava nas masturbações do anedotário e das atoardas, na curiosidade protocolar - “então, novidades?" e mal daqueles que não as conhecesse ou que não tivesse imaginação para as urdir -, a cadeira, no café, a roçar a cadeira de um secreta, todos, afinal, coabitando com ódios mas sem brigas, com o decoro das abulias, pondo honestamente a sua assinatura nos protestos colectivos, arredando a promiscuidade das realidades cruéis. (idem: 208)

Em suma: a clandestinidade heroica da juventude animada pelos propósitos de emancipação social adoeceu em clandestinidade reles preocupada em preservar a aparente compostura de uma existência sórdida.

A trama do romance acontece em menos de uma hora: Vasco Rocha espera Jacinta num quarto da casa de Bárbara. E está disposto a não esperar muito, está disposto 
a pôr fim a esta clandestinidade afetiva, que concentra todas as cedências e conformismos em que transformou a sua vida. Quer reencontrar um Vasco "que talvez nunca houvesse existido ou só existiria através da determinação em o reconstituir” (idem: 278). Vai telefonar ao marido de Jacinta e desvendar-se. 0 romance termina aí. Bárbara pergunta-lhe: “Então, filho, vais-te embora?”. Vasco responde: “Vou. Mas antes, precisava de telefonar”.

Há boas razões, suponho, para ler Os Clandestinos como a segunda peça de um tríptico de que o primeiro momento seria Fogo na Noite Escura, o romance da juventude como consciência da luz. Tudo o que é afirmativo, convicto, solar em Fogo na Noite Escura é, em Os Clandestinos, incerto e crepuscular. Ficamos, no entanto, suspensos do telefonema, cujo desenlace desconhecemos: no meio das cinzas, Vasco Rocha quer (re)encontrar uma possibilidade de si mas não sabemos se o conseguiu.

0 romance seguinte, $O$ Rio Triste, se o considerarmos como o terceiro momento desse eventual tríptico, encerra o percurso ficcional de Namora com "nenhum otimismo". Corresponde ao que o narrador, romancista, exige do romance: "o romance tem de ser uma soma, um inventário, um suicídio torrencial, apocalíptico. Uma enxurrada de vida a desprender-se num abismo. Um romance é um ato derradeiro, um testamento" (Namora 1992: 190). À primeira vista, a experiência da juventude e o seu conflito com o conformismo social parecem menos presentes: mas só porque o olhar se distanciou, porque a paisagem histórico-existencial é mais ampla, porque a galeria de personagens percorre vários graus de ocultamento, de furtividade, de disfarce. Mesmo assim, no interior dessa desolação simultaneamente política e individual, a interrogação ocorre: "que fizera ele dessa juventude - ou fora ela já um levedor de rancores? (E que fiz eu próprio da minha, vá, responde, André Bernardes, somos todos uma pobre caricatura)” (idem: 99). Como se o propósito desesperado de romper o conformismo social ainda não estivesse extinto, como se uma saída ainda fosse possível. Em O Rio Triste - repito: o derradeiro romance de Fernando Namora - a saída não podia ser mais enigmática: “No dia 14 de Novembro de 1965, nesta cidade de Lisboa, um homem saiu cedo de casa e já não voltou” (idem: 7). Como é desaparecer? Não é, por certo, simplesmente, o contrário de aparecer. A vida trivial de Rodrigo dos Santos Abrantes mantivera-o numa forma de anonimato. Paradoxalmente, "uma vida vulgar (...), de uma hora para a outra, surge perante as pessoas carregada de equívocos e labirintos” (idem: 129). Um clandestino de que clandestinidade? 0 romance não responde. Ou melhor: a rutura com a "atmosfera demencial" em que "somos prisioneiros" foi-se tornando um problema cada vez mais complexo (complexo, quer dizer: envolvendo um conjunto de variáveis cada vez mais incontroladas por um pensamento transformador).

7.

A oportunidade de pensar essa complexidade, e não, simplesmente, descrever o seu funcionamento no dispositivo ficcional, surgiu com o convite para que Fernando 
Namora participasse nos Encontros Internacionais de Genebra que, em 1965, decorreram sob o tema: “O robot, o animal e o homem - Para uma definição do humano". Regressado de Genebra, a crónica em que sintetizou a densidade da sua experiência e a riqueza dos debates acabou por ganhar a forma de Diálogo em Setembro, a obra mais extensa e ambiciosa de Fernando Namora e uma viragem decisiva na sua reflexão e na sua escrita. Como tem sido amplamente notado, Diálogo em Setembro obriga Fernando Namora a deslocar-se para uma outra escala: o "inventário do homem português” é integrado num território geográfico e antropológico mais amplo. Sobretudo, incita Namora a uma exploração (de certo modo, uma outra “inventariação") dos problemas inerentes a uma viragem civilizacional:

O Homo Sapiens foi criado e criou um meio em que a natureza a todo o momento o comprometia. Hoje, é possível ignorar a natureza, desconhecer os céus, dispensar as árvores, é possível viver em climas artificiais, substituir o sol e as ervas e impor ainda à fisiologia que acelere a sua adaptação às ambiências para que não foi preparada. Mas pergunta-se que homem surgirá dessa ruptura com o meio natural (...) Somos apenas os (...) paleos da era neotécnica. (Namora 1997: 190)

Se poderá não ser excessivo afirmar que essa questão já estava pressentida na trama romanesca da rutura com a terra (em Minas de San Francisco, por exemplo), a partir de Diálogo em Setembro, ganha outra dimensão e outra densidade que requerem outra escrita: chamar-lhe “crónica romanceada”, expressão que na voluntária baixa intensidade do seu paradoxo é tímido em relação ao propósito. Crónica, no sentido em que se propõe reportar o que aconteceu, ou melhor: em que um escritor pretende reportar o que aconteceu, o que logo torna o texto ficcional, porque toda a escrita mediada pela memória é ficcional.

O ciclo aberto por Diálogo em Setembro e continuado em Os Adoradores do Sol (1971), Estamos no Vento (1974), Cavalgada Cinzenta (1977) e Sentado na Relva (1986), repercute as preocupações, que lhe são contemporâneas, de um Herbert Marcuse ou do Daniel Bell de A Sociedade Pós-Industrial (1973) e antecipa o que, cronologicamente mais perto de nós, ocorre na reflexão de um Byung-Chul Han em A Sociedade do Cansaço (2014).

Fernando Namora toma de empréstimo uma expressão de E. Mounier para identificar as caraterísticas de sociedades com o tipo de desenvolvimento da Escandinávia: a “doença da felicidade” (Namora 1997: 38). No quadro de um neo-capitalismo robustecido, "o sistema (...) aboliu a miséria e a intranquilidade, democratizou a cultura, (...) espevitou a economia, distribuiu o bem-estar" (idem: 39): e "encontrou-se perante a monotonia e o enfado" (idem: 190).

“À escuta do mundo" (Namora 1998: 156), os movimentos juvenis têm procurado prevenir-se contra a contaminação dessa “doença da felicidade”. Na "narrativa literá- 
rio-sociológica" que é Estamos no Vento, o escritor (o narrador) situa um (ficcionado?) diálogo com os netos na reconstrução alargada dos fundamentos, das formas e dos estereótipos desses movimentos juvenis, pelo menos desde os anos 60 holandeses. Não porque neles resida uma alternativa ou sequer uma proposta programática, não porque eles sejam o modelo para uma futura reconfiguração social mas porque as suas insubmissões, recusas, insolências e excessos constituem "um sinal" (Namora 1997: 141).

O que defendiam, esses jovens holandeses? A proibição da circulação dos automóveis no centro de Amesterdão e o recurso sistemático à bicicleta, a discussão da proibição do comércio de drogas, a defesa do recurso sistemático aos preservativos, a sinalização de prédios devolutos e a sua eventual ocupação.

Percebemos: o que (talvez apressadamente) foi batizado como contracultura encerra em si uma surpreendente dimensão premonitória, capaz de desassossegar mesmo os olhos cansados e inquietos do século XXI - se eles (ainda) forem capazes de identificar os sinais.

No seu impressionante ensaio de compreensão, Namora identifica a juventude com a capacidade de identificar esses sinais. 0 seu interesse não foi valorizar, sequer historiar o modo como os movimentos juvenis responderam ou não à diversidade de circunstâncias históricas.

O propósito foi outro: juventude como condição e exigência trans-histórica revela-se no "segredo de olhar do Sol de frente" (Namora 1988: 207).

A expressão encontra-se em Jornal Sem Data (1988), sua obra derradeira. E, não por acaso, no comovido depoimento escrito sob o impacto da morte de Joaquim Namorado, Amigo de toda a vida: "Joaquim Namorado está vivo - em todos os muitos jovens que o tinham como o companheiro de quem se recebe o segredo de olhar o Sol de frente. Pois só a juventude pode olhar assim" (idem: 206-207).

\section{Notas}

\footnotetext{
* António Pedro Pita é Professor catedrático da Faculdade de Letras e Investigador do Centro de Estudos Interdisciplinares do Século XX - CEIS2O da Universidade de Coimbra. Membro do Conselho Científico da Faculdade de Letras (UC), do Centro de Estudos Ibéricos, do Conselho Consultivo da AIM - Associação de Investigadores da Imagem em Movimento e do Grupo "Relire l'entre-deux-guerres”, do Conselho Consultivo da Associação da Casa da Achada-Centro Mário Dionísio, de que é sócio fundador e do Grupo de Pesquisa “Intelectuais e poder no mundo iberoamericano" (Universidade do Estado do Rio de Janeiro - UERJ). Pertence ao Comité Científico de várias publicações científicas, nacionais e estrangeiras e é Professor visitante na Pontifícia Universidade Católica do Rio de Janeiro e na Universidade
} 
de Santiago de Compostela. Investiga e publica sobretudo nas áreas da filosofia contemporânea, do pensamento estético e das relações entre arte e política, com destaque para o neorrealismo.

' $O$ presente texto fixa a arquitetura e o desenvolvimento da comunicação, tal como foi apresentada no Colóquio "Literatura e Medicina. Homenagem a Fernando Namora no Centenário do seu nascimento". Agradeço à Profa Doutora Maria de Lurdes Sampaio e ao Prof. Doutor Fernando Batista a honra do convite. Quanto à atual versão: a sua dimensão voluntariamente ensaística dispensa-me, de momento, de todas as exigências bibliográfico-eruditas, que serão consideradas se e quando a matéria deste ensaio, que é uma questão central, se transformar em estudo (ou capítulo) da trajetória literária de Fernando Namora.

${ }^{2}$ Cf. a obra já clássica de Reinhart Koselleck, Futuro Passado. Contribuição à Semântica dos Tempos Históricos [1979], Rio de Janeiro, Contraponto, Ed. PUC-Rio, 2006. Em particular, o capítulo intitulado “'Espaço de experiência’ e 'horizonte de expetativa’: duas categorias históricas”, pp. 305-327.

${ }^{3}$ A categoria de "relação", com a relevância que se pressupõe no texto, exige uma tematização autónoma.

${ }^{4}$ Permito-me a remissão para um estudo onde a questão é amplamente tratada. Cf.: António Pedro Pita, "Conflito e unidade do neo-realismo português", Porto, Campo das Letras, 2002. Para a citação de "Cadernos da Juventude", p. 17.

${ }^{5}$ Trata-se da Edição das Obras Completas de Fernando Namora dirigida por José Manuel Mendes. Salvo indicação diversa, todas as obras de Fernando Namora serão citadas a partir desta Edição exemplar.

${ }^{6}$ Elaborar a consciência da experiência histórica (o que pressupõe a possibilidade dessa elaboração) é uma exigência da trama pré-conceitual do neorrealismo.

7 "A juventude tem uma voz profética” (F. Namora, Um Sino na Montanha, p. 167).

${ }^{8}$ A questão referida neste parágrafo (a saber: a "rutura" com a terra) permite ligar o período em que Namora incidiu na sociedade portuguesa com o período da ampliação europeia (e mundial) da sua atenção. Não sendo, porém, o tema desta comunicação, prefiro reservar a sua abordagem para uma outra oportunidade.

\section{Bibliografia}

Deleuze, Gilles (1990), Pourparlers, Paris, Les Editions de Minuit. Han, Byung-Chul (2014), A Sociedade do Cansaço, Lisboa, Relógio D’Água. Koselleck, Reinhart (2006), Futuro Passado. Contribuição à Semântica dos Tempos Históricos [1979], Rio de Janeiro, Contraponto, Ed. PUC-Rio Namora, Fernando (1996) [1943], Fogo na Noite Escura, Lisboa, Círculo de Leitores.

-- (1987), Autobiografia, Lisboa, Edições O Jornal.

-- (1988), Jornal Sem Data, Lisboa, Bertrand Editora. 
-- (1996) [1945], A Casa da Malta, Lisboa, Círculo de Leitores.

-- (1997) [1957], O Homem Disfraçado, Lisboa, Círculo de Leitores.

-- (1997) [1966], Diálogo em Setembro, Lisboa, Círculo de Leitores.

-- (1997) [1971], Os Adoradores do Sol, Lisboa, Círculo de Leitores.

-- (1997), Um Sino na Montanha, Lisboa, Círculo de Leitores.

-- (1998) [1972], Os Clandestinos, Lisboa, Círculo de Leitores.

-- (1998) [1974], Estamos no Vento, Lisboa, Círculo de Leitores.

-- (1998) [1977], Cavalgada Cinzenta, Lisboa, Círculo de Leitores.

-- (1998) [1986], Sentado na Relva, Lisboa, Círculo de Leitores.

-- (1998) [1992], O Rio Triste, Lisboa, Círculo de Leitores. 